Original article

\title{
COVID-19: District level vulnerability assessment in India
}

\author{
Apurba Sarkar ${ }^{\mathrm{a}, *}$, Pradip Chouhan ${ }^{\mathrm{b}}$ \\ ${ }^{a}$ Research Scholar of Department of Geography, University of Gour Banga, Malda, West-Bengal, 732103, India \\ ${ }^{\mathrm{b}}$ Department of Geography University of Gour Banga, Malda, West-Bengal, 732103, India
}

\section{A R T I C L E I N F O}

\section{Keywords:}

COVID-19

Pandemic

Vulnerability

Composite index

Community risk

\begin{abstract}
A B S T R A C T
Objectives: COVID-19 Pandemic has brought a threatening challenge to the world and as well as for Indian society and economy. In India, it has become a public health disaster and its' intensity increasing continuously. For the disaster risk reduction, and capacity building against the COVID-19 pandemic understanding of the relationship between socio-environmental conditions with the pandemic is very necessary. The objective of the present work is to construct a socio-environmental vulnerability index of the potential risk of community spread of COVID-19 using socio-economic and environmental variables.

Methodology: In this, cross-sectional study principal component analyses have been used to drive SoEVI. 4 uncorrelated sub-index has been extracted from 16 sub-indicators which reflects $59 \%$ of the variance. Aggregation of 4 Sub-Index has been done to obtain the final vulnerability Index.

Results: Results show that there is spatial variability in vulnerability based on environmental and socio-economic conditions. Districts of north and central India found more vulnerable then south India. Statistical significance has been tested using regression analysis, positive relation has been found between vulnerability index and confirmed and active cases.

Conclusion: The vulnerability index has highlighted environmentaly and socioeconomicallybackward districts. These areas will suffer more critical problems against COVID-19 pandemic for their socio-environmental problem.
\end{abstract}

\section{Introduction}

India is the 2nd largest country in terms of population and 6th leading economy in the world. ${ }^{1}$ But COVID-19 has brought a threatening challenge to the Indian society and economy. The major challenge is to provide basics medical facilities to the huge numbers of incoming infected people if, the community spread takes place in the vast territory. Initially, the introduction of lockdown in the early stage of spreading has controlled the number of cases and restricts the community spread ${ }^{2,3}$ eventually, but the question is how long it would be possible for India to stay at the home closing door of economic. The economic shutdown is not the permanent solution from this pandemic this emergency demand more constructive socio-economic and public health reforms form a political and apolitical organization.

A prototype growth pole model that has been followed by India from the post-independent era ${ }^{4}$ is enough to combat the emergency, or it has major fallacy to overcome the situation? India has to rethink its rural developmental policy and public health infrastructure improvement that has failed to remove regional imbalance. ${ }^{5,6}$ The situation is quite different for India what the developed world experienced in controlling the situation. ${ }^{7}$ The situation of India is more critical for its huge population, poor infrastructure, and complex socio-economic structure, ${ }^{8}$ where self-isolation, social distancing, and quality treatment is the key controlling factors to neutralize the impact of disease. ${ }^{9-12}$ Inter-state migration of labor in the lockdown period has brought challenges to controlled community spread. Arrangement of quarantine for a huge number of populations is a major task for the local governing body. ${ }^{13}$ The government has compelled to change policy and promote home quarantine but how much it is possible in India. $42 \%$ of households are living in a condition where, three or more people are sharing a single room (Census, 2011) ${ }^{14}$ Not only that there is a shortage of Public health institutions, medical equipment ( 0.7 hospital beds per 1000 people), doctors, nurses (doctor: population ratio is 1: 1800). ${ }^{15}$ National Health family survey (NHFS- 4 ) shows that only $80 \%$ population of Kerala have the accessibility of health care facilities within $5 \mathrm{~km}$ but the situation is very worst for the state like Bihar, Jharkhand, Madhya Pradesh. ${ }^{16}$ When

\footnotetext{
* Corresponding author. University of Gour Bang, GoalparaDebinagarRaiganj, Uttar-dinajpur, West-Bengal, PIN 733123, India.

E-mail addresses: apurbasarkar.ugb@gmail.com (A. Sarkar), pradipchouhanmalda@gmail.com (P. Chouhan).
} 

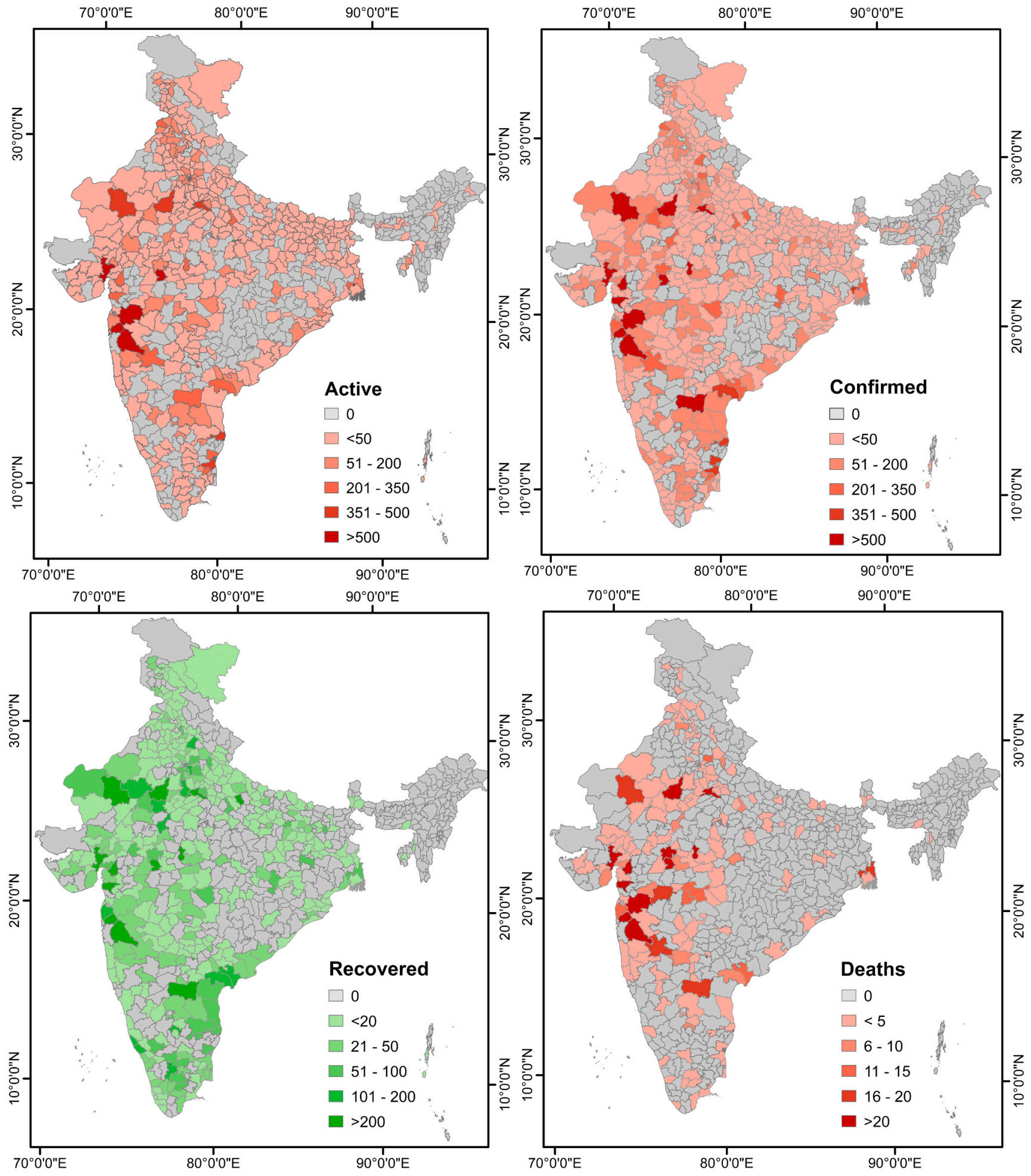

Fig. 1. District wise Active, Confirmed, Recovered and Deaths cases as on 14 May

Chain efficiently escapes from danger with the help of equipped public health infrastructure despite of the largest population share in the world $^{17,18}$ while India is facing huge trouble with its inadequate infrastructure.

Poor public health infrastructure is the main limitation and strategic disadvantage against pandemic, it increases the chances of the risk of exposure to vulnerability. ${ }^{19,20}$ Post epidemic management strategy of a developing country has a policy-oriented dispute post epidemic managemental policy are given more priority then preepidemic management consequently, mass level public health infrastructure improvement is given less importance. Another problem is the medicinal approaches to overcome the situation without considering the socio-economic problem like poverty, educational backwardness, and awareness. But these socio-economic parameters have great influences on vulnerability, adverse socio-economic conditions increase the inability to withstand the effects of a hostile situation. ${ }^{21}$

District wise confirmed, active, recovered and deaths cases represent in Fig. 1. The figure shows that the epidemic has spread across the states, 

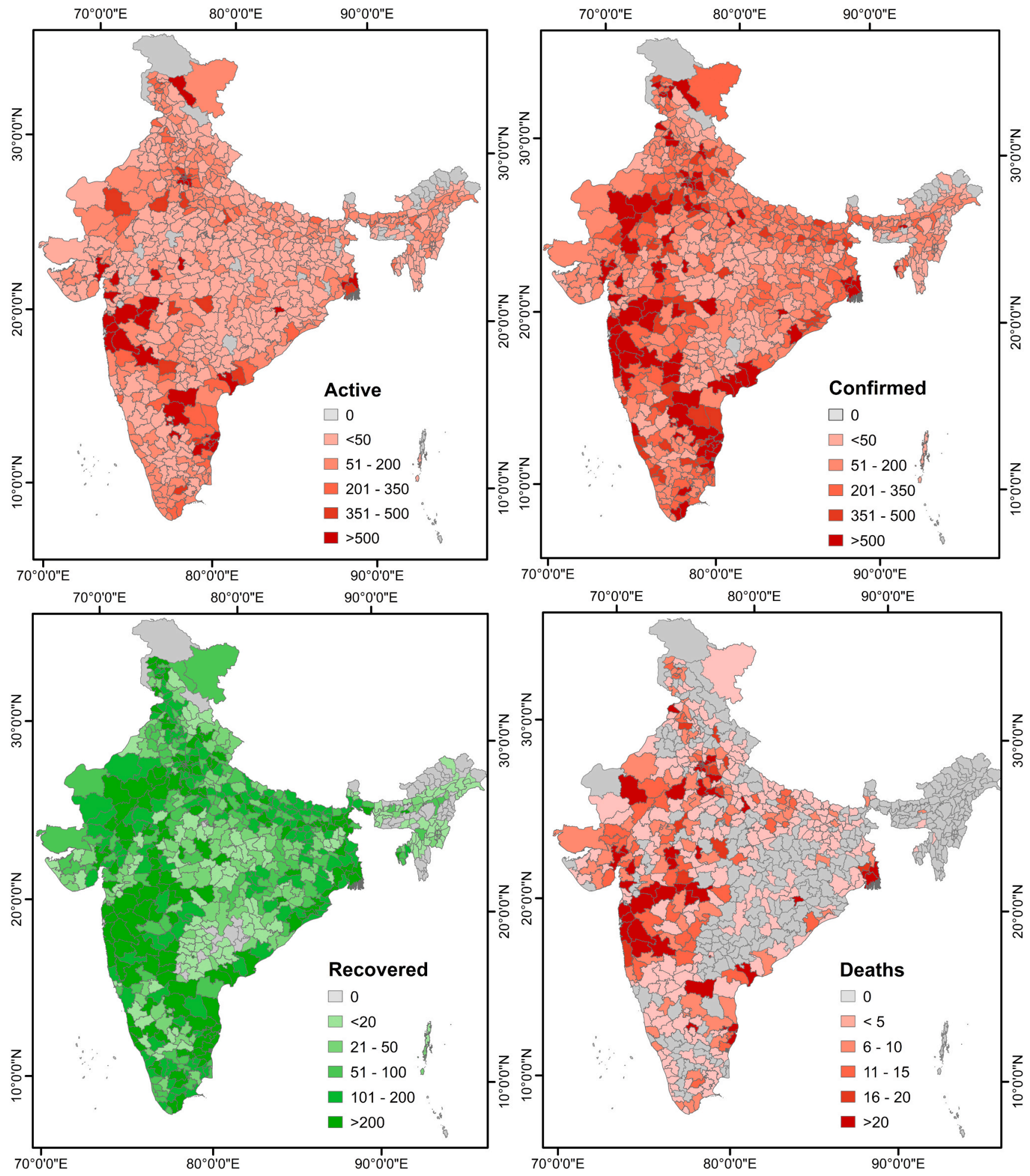

Fig. 2. District wise Active, Confirmed, Recovered and Deaths cases as on 25 June.

most of the districts have a footprint of contamination. Death has increased considerably within the month. The total case fatality rate is $2.8 \%$ and death per 1lack population is $0.49 .^{22}$ Which is very controlled and marginalized in comparison to other countries (Fig. 2). But the major concern is the rate of the new confirmed case is very high and continuously rising. High co-morbidity is one of the important aspects in India. Many researchers predict that the condition will be more critical in winter ${ }^{23,24}$ due to the favorable climatic condition and high co-morbidity. ${ }^{25}$ A surge in transition will be expected if the vaccine has not been introduced. ${ }^{26}$ That will create huge pressure on the public health system. The present investigation has been selected to identify Socio-environmentally venerable districts that will be facing most more hurdles against pandemic for their socio-economic backwardness.

Vulnerability refers to the condition where the risk to exposure of community increase toward the hazard. ${ }^{27,28}$ Vulnerability is a multidirectional aspect. According to Bizimana 2015 'Vulnerability to natural hazards refers to the conditions determined by physical, social, economic, and environmental factors that increase the susceptibility of a 
Table 1

Selected indicators for vulnerability Assessment.

\begin{tabular}{|c|c|c|c|}
\hline Index & Variables & Influence & Sources \\
\hline NO2 & $\mathrm{NO}_{2}$ & + & Central Pollution \\
\hline MP2.5 & $\mathrm{PM}_{2.5}$ & + & Controlled Board \\
\hline PM10 & PM10 & + & \\
\hline $\mathrm{SO} 2$ & $\mathrm{SO} 2$ & + & \\
\hline HHD & $\begin{array}{l}\text { House Hold Density (House Hold/ } \\
\mathrm{Km} 2 \text { ) }\end{array}$ & + & $\begin{array}{l}\text { Census of India, } \\
2011\end{array}$ \\
\hline PD & Population Density (Person/Km2) & + & \\
\hline LITR & Literacy Rate & - & \\
\hline HLP & $\begin{array}{l}\text { Houseless population (person per } \\
\text { thousand) }\end{array}$ & + & \\
\hline $\mathrm{EP}$ & Elderly population (\%) & + & \\
\hline MC & Muslim Population (\%) & + & \\
\hline SCST & SC and ST Population (\%) & + & \\
\hline SEXR & $\begin{array}{l}\text { Sex Ratio (female/per thousand } \\
\text { male) }\end{array}$ & - & \\
\hline WFP & Workforce participation rate (\%) & - & \\
\hline HHLI & $\begin{array}{l}\text { Percentage of household having } \\
\text { monthly income of highest-earning } \\
\text { member }<5000\end{array}$ & + & $\begin{array}{l}\text { Socio-Economic } \\
\text { Caste Census-2011 }\end{array}$ \\
\hline PHII & Public Health Infrastructure Index & - & $\begin{array}{l}\text { Ministry of health } \\
\text { and family welfare }\end{array}$ \\
\hline DMC & $\begin{array}{l}\text { Distance from selected urban Center } \\
\text { (in m.) }\end{array}$ & - & Open street map \\
\hline
\end{tabular}

Table 2

Rotated component Matrix.

\begin{tabular}{llllll}
\cline { 1 - 4 } Variables & \multicolumn{2}{l}{ Component } & \multirow{2}{*}{ Communality } \\
\cline { 2 - 4 } & 1 & 2 & 3 & 4 & \\
\hline $\mathrm{PM}_{10}$ & $\mathbf{0 . 8 4 0}$ & 0.134 & 0.31 & 0.14 & 0.841 \\
$\mathrm{NO}_{2}$ & $\mathbf{0 . 7 8 2}$ & 0.361 & 0.049 & -0.119 & 0.757 \\
$\mathrm{PM}_{2.5}$ & $\mathbf{0 . 7 6 6}$ & 0.156 & 0.285 & 0.227 & 0.743 \\
$\mathrm{SO}_{2}$ & $\mathbf{0 . 7 4 8}$ & 0.042 & -0.083 & -0.076 & 0.575 \\
$\mathrm{HHD}$ & 0.072 & $\mathbf{0 . 8 8 1}$ & 0.054 & -0.037 & 0.785 \\
$\mathrm{PD}$ & -0.038 & $\mathbf{0 . 8 0 7}$ & 0.16 & -0.069 & 0.683 \\
$\mathrm{HHLI}$ & -0.277 & $-\mathbf{0 . 7 2 7}$ & -0.093 & 0.049 & 0.617 \\
$\mathrm{HLP}$ & 0.268 & $\mathbf{0 . 5 1 3}$ & -0.16 & -0.008 & 0.361 \\
$\mathrm{UPD}$ & 0.187 & $\mathbf{0 . 3 7 8}$ & -0.052 & -0.014 & 0.181 \\
$\mathrm{DMC}$ & 0 & $\mathbf{0 . 3 5 1}$ & 0.214 & -0.155 & 0.179 \\
WFP & 0.243 & 0.146 & $\mathbf{0 . 7 9 8}$ & 0.044 & 0.718 \\
$\mathrm{RPD}$ & 0.237 & -0.149 & $\mathbf{0 . 7 6 2}$ & -0.133 & 0.677 \\
MC & -0.161 & 0.077 & $\mathbf{0 . 7 2 3}$ & 0.177 & 0.586 \\
SCST & -0.296 & -0.113 & $-\mathbf{0 . 5 5 6}$ & 0.549 & 0.711 \\
EP & -0.012 & -0.046 & -0.084 & $\mathbf{0 . 8 6 2}$ & 0.753 \\
PHII & -0.036 & -0.199 & -0.164 & $\mathbf{0 . 6 4 7}$ & 0.487 \\
LITR & 0.134 & -0.363 & 0.116 & $\mathbf{0 . 5 2 2}$ & 0.436 \\
SEXR & 0.376 & 0.247 & 0.216 & $\mathbf{0 . 4 8 2}$ & 0.481 \\
Initial eigenvalue & 4.561 & 2.479 & 1.997 & 1.527 & \\
Rotated Eigenvalue & 3.043 & 2.941 & 2.44 & 2.142 & \\
\% of Variance & 25.344 & 13.776 & 11.096 & 8.484 & \\
\hline
\end{tabular}

Extraction Method: Principal Component Analysis.

Rotation Method: Varimax with Kaiser Normalization.

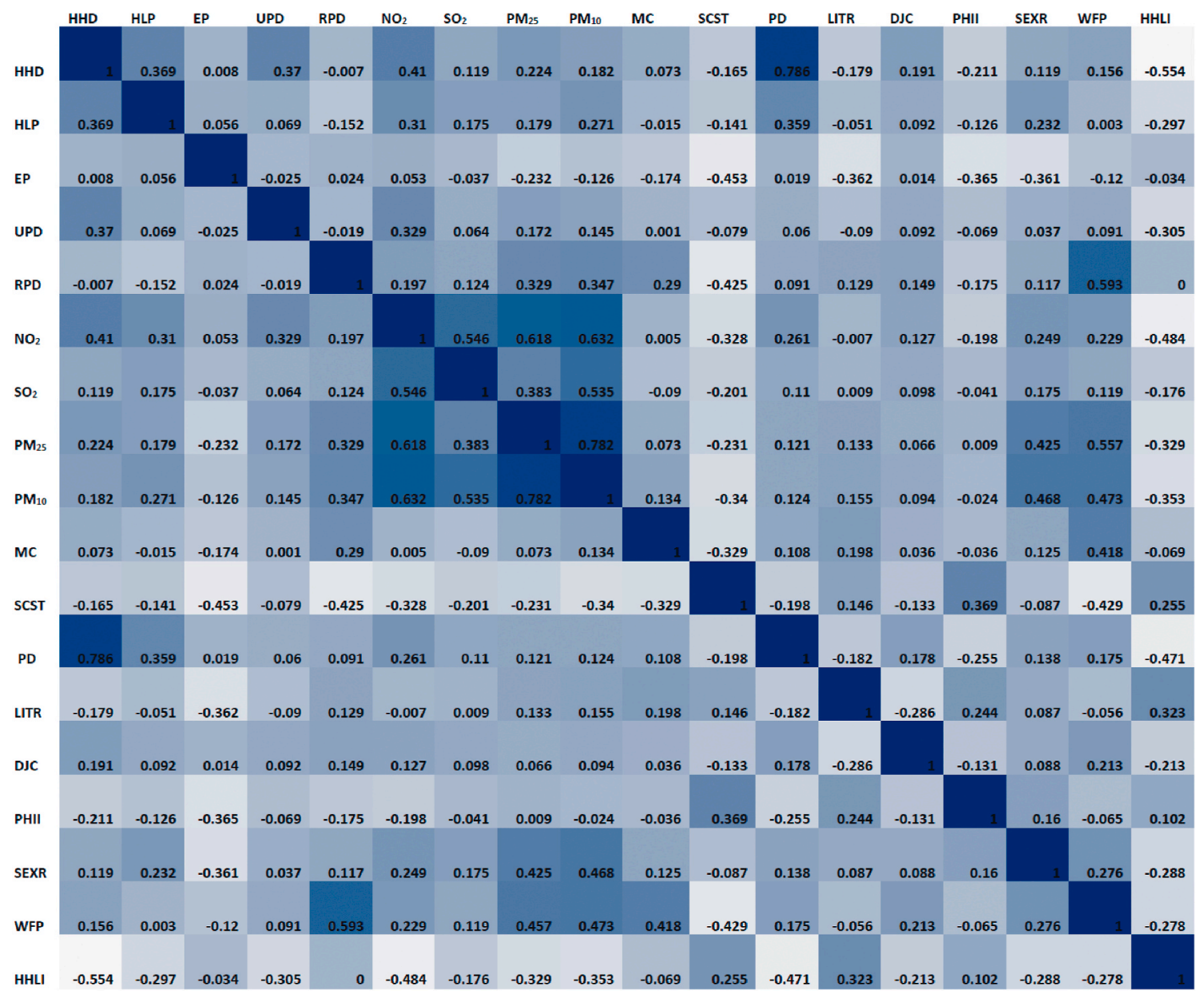

Fig. 3. Pearson correlation Matrix of indicators. 


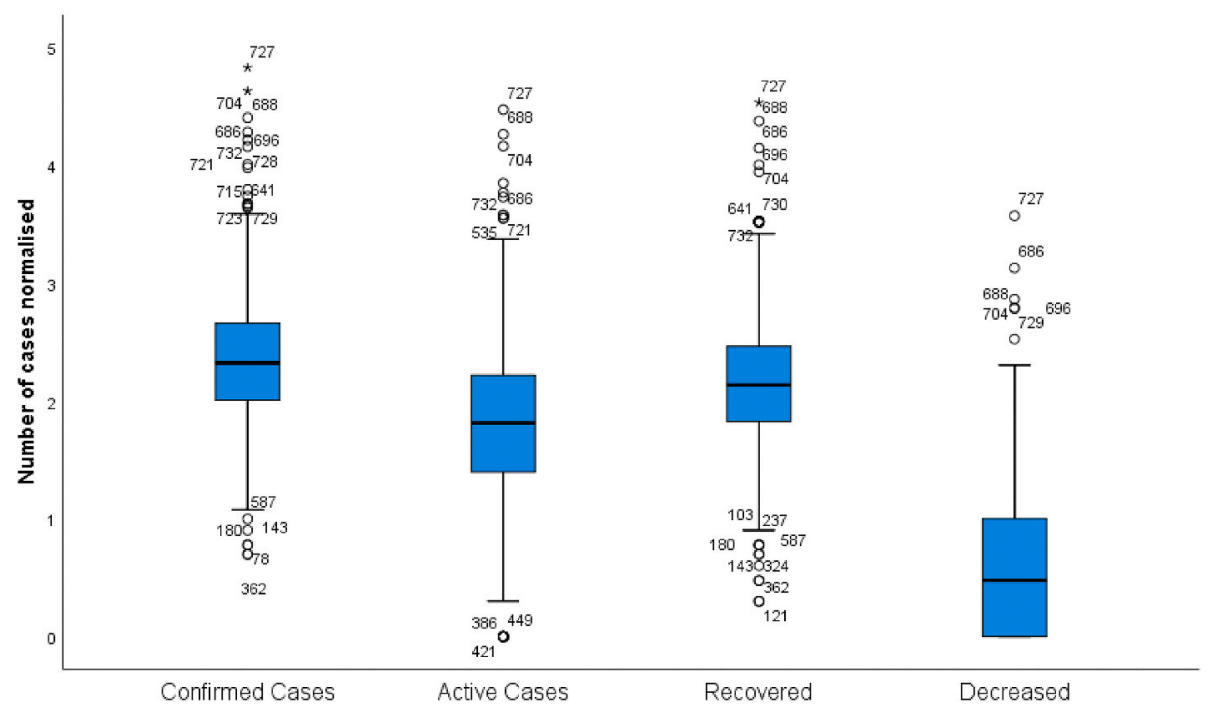

Fig. 4. Severity of COVID-19 cases confirmed, active, recovered, decreased as on 25 June.

Table 3

Pearson correlation matrix of SoEVI and confirmed, active, recovered, decreases cases.

\begin{tabular}{|c|c|c|c|c|c|}
\hline & SoEVI & $\begin{array}{l}\text { Confirmed } \\
\text { Cases }\end{array}$ & $\begin{array}{l}\text { Active } \\
\text { Cases }\end{array}$ & Recovered & Decreased \\
\hline SoEVI & 1 & & & & \\
\hline $\begin{array}{l}\text { Confirmed } \\
\text { Cases }\end{array}$ & 0.381 & 1 & & & \\
\hline Active Cases & 0.224 & 0.916 & 1 & & \\
\hline Recovered & 0.297 & 0.96 & 0.802 & 1 & \\
\hline Decreased & 0.388 & 0.79 & 0.693 & 0.772 & 1 \\
\hline
\end{tabular}

community to hazards'. To develop strategies against vulnerability needs knowledge regarding the social, economic, and political factors that trigger the vulnerability and the factors helps to built up adaptive capacity. ${ }^{29}$

\section{Method}

For social vulnerability assessment of newly address diseases, highlights should be given on the importance of social aspects that makes communities or individuals more susceptible to the infection. ${ }^{30}$ In this crossectional study quantitative statistical techniques have been used to contract Composite Index. Composite index constricted with socio-economic indicators reflect the real-world complexity in a very simplified manner on a comparable scale. Researchers employed composite indicators as an essential tool to assess vulnerability and understand the pattern of disparity. The major advantage of the composite indicator is it allows comparisons to be made across different geographical areas.

\subsection{Variable selection}

Variable selection is a very crucial part of vulnerability assessment. There is a lake of information regarding triggering factors that make the COVID-19 pandemic more susceptible to a particular community. Many scholars give emphasize socio-economic and environmental ${ }^{31}$ determinants, which can have a considerable effect on COVID-19 Pandemics. ${ }^{32}$ Homeless families are at higher risk of viral transmission because of crowded living that increases the risk of transmission. ${ }^{33}$ The number of Houseless population (person per thousand) in districts have been taken as a variable. In any society, the economically weaker section has limited access to resources, health facilities that make them
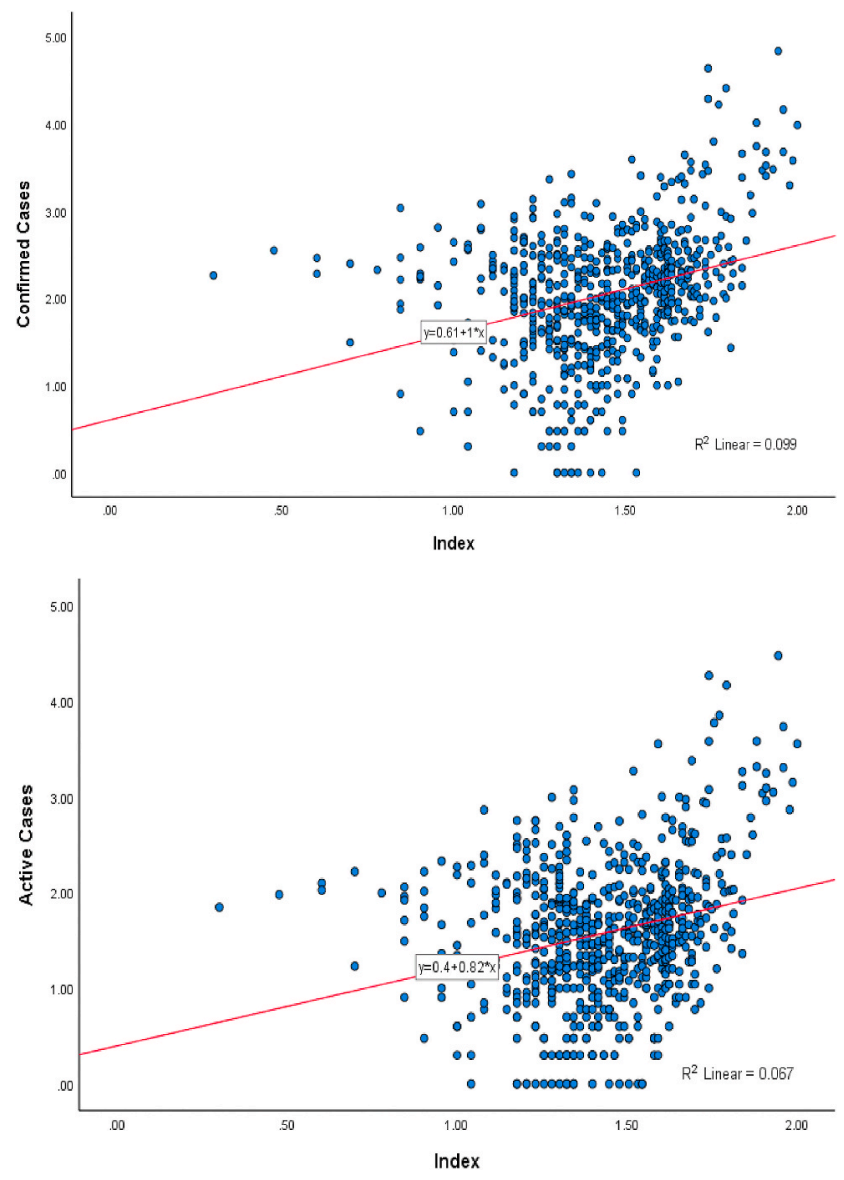

Fig. 5. Relation between SoEVI and confirmed and active cases.

vulnerable to the disease. Economic factors like Unemployment, low-income households are more likely to be infected because of stay at home is not possible for the theme. Europe experienced Black Death in the 14th century that takes away a huge life. The highest number of fatalities observed among the underprivileged populations ${ }^{34}$ hence the percentage household having low-income, people belong to backward class; Scheduled caste Schedule tribe, Muslim population, and low workforce participation rate have been considered as variables. 


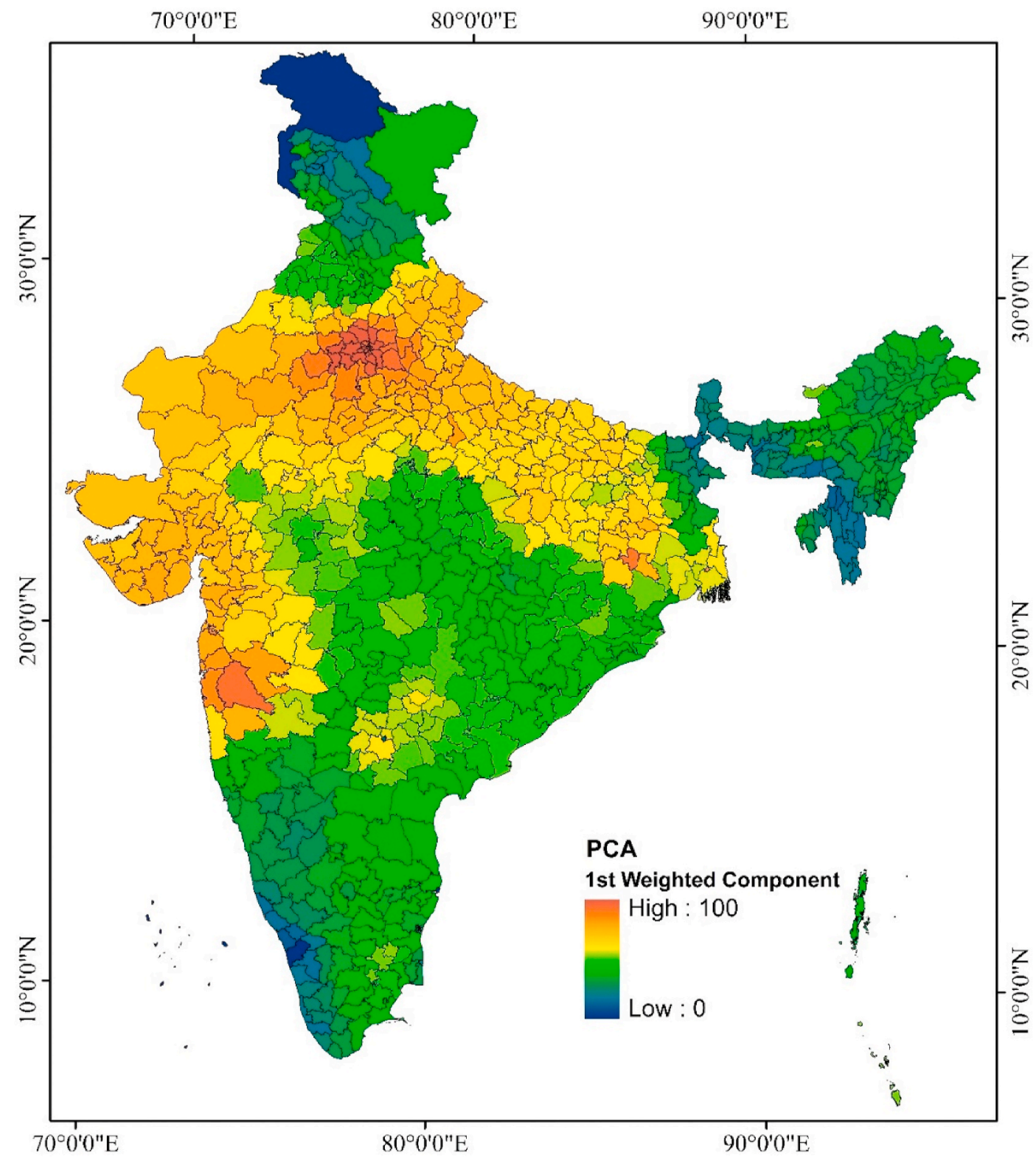

Fig. 6. Environmental vulnerability.

Population density, household density, taken into consideration because population concentration, high density may cause rapid community spread. Human exposure to prolong air pollution increases the risk of respiratory disease they are more susceptible to COVID-19. ${ }^{35}$ The annual average of air pollutants; $\mathrm{NO}_{2}, \mathrm{SO}_{2}, \mathrm{PM}_{10}, \mathrm{PM}_{2.5}$ of 2018 has taken as variables, these are the point source data collected from Central Pollution Controlled Board (CPCB) under the project of National Ambient Air Quality Monitoring Programme (NAMP). ${ }^{36}$ Percentage of the elderly population to the total population is considered as variables because the elderly population is more susceptible to the diseases for their fragile immunity. People who have a chronic respiratory problem are at higher risk of infection. ${ }^{37}$ Accessibility of public health infrastructure (PHI) is one of the key components of epidemic management. ${ }^{38,39}$ A huge number of low and middle-class people dependent on PHI. ${ }^{6,40}$ Deficiency of PHI or fragile PHI creates inequality in public health accessibility. Public health infrastructure index has been constructed using the district-wise number of the sub-health center, primary health centres, community health centres, Health \& Wellness Centres-Sub Centres, Health \& Wellness Centres- Primary Health Centres, sub-district hospital, district hospital, and Medical College. Literacy and sex ration are important social factors that indicate social equality. Low level of education creates a lack of consciousness this creates confusion regarding the disease. Sometimes people deny taking medical assistance from the government in an emergency due to miss information regarding the treatment of disease (Table 1).

Before constrict PCA data normalization has been performed using ZScore. The Z-score is a widely used statistical technique that can able to standardize a wide range of data to represent the significant changes across the data. ${ }^{41} \mathrm{Z}$-score data normalization has been done using the following formula ${ }^{42}$

$\mathrm{Z}_{\mathrm{i}}=\frac{X_{i}-\bar{X}}{\sigma}$

Normalization has been done to avoid large differences in scale or variance between variables. After the normalization. Those parameters have a negative relationship with a vulnerability which means high value indicates low vulnerability vice versa is reversed by multiplying with $(-1)$. These make date unidirectional and make it easy for the interpreter. 


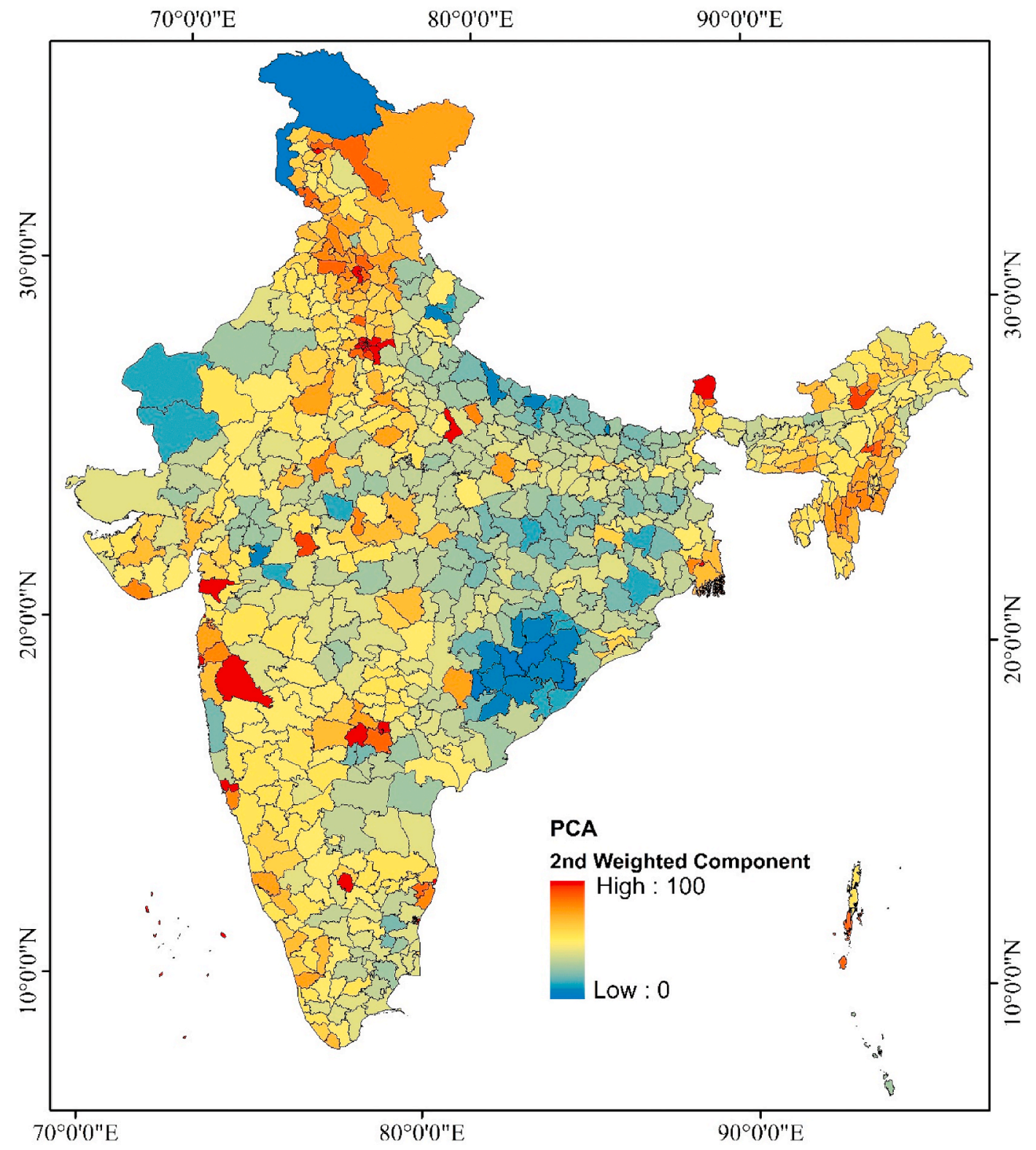

Fig. 7. Economic and Demographic vulnerability.

\subsection{Principal component analysis (PCA)}

The principal component analysis is a popular multivariate statisti$\mathrm{cal}^{43}$ method employed to find out suitable variables that explained the phenomena at an optimum level. PCA helps to reduce the dimensionality of data ${ }^{44}$ into a comparable component that preserved the originality of data. ${ }^{45-47}$ Our purpose is to reduce the dimensionality of a set of variables preserving as much information from the original variables ${ }^{48}$ as possible. In such a case, principal component analysis is the most accepted suitable methodology. ${ }^{49}$ This data transformation technology transformed highly co-related data into an uncorrelated component ${ }^{50} \mathrm{~A}$ component that eigenvector greater than 1.5 is considered for the construction of the index.

\subsection{Aggregating indicators}

There are no universal rules of assignee weight. Musse at al 2018 et al. uses component score as variables and multiplies with the percentage of variables as weight. Mishra 2018 assigned factors lodgings as weight and construct index with multiplying with normalized vari- ables. ${ }^{51}$ In this study similar approached of Musses et al., 2018 has been used. 16 indicators have been selected for the PCA (Table 1). Based on initial eigenvectors 4 components have been extracted. Component eigenvector grater then 1.5 is considered for the index creation. The score of the component has been used as a variable $\left(f_{i}\right), \%$ of the total variance of each component has been used as a weight $\left(W_{\mathrm{i}}\right)$. New variables have been derived from multiplying each component score with its weight. Socio-environmental vulnerability index has been derived using the following formula-

$\mathrm{SoEVI}=\sum_{1}^{n} f_{i} w_{i}$

where SoEVI $=$ Social vulnerability index $\mathrm{n}$ is the number of components extracted from PCA $f_{i}$ is component score and $w_{i}$ is the percentage of variance explained by the component. For easy interpretation of the results, the final index values have been normalized within a new range from 1 to 100, where 1 reflects a very low vulnerability and 100 indicate high very vulnerability. 


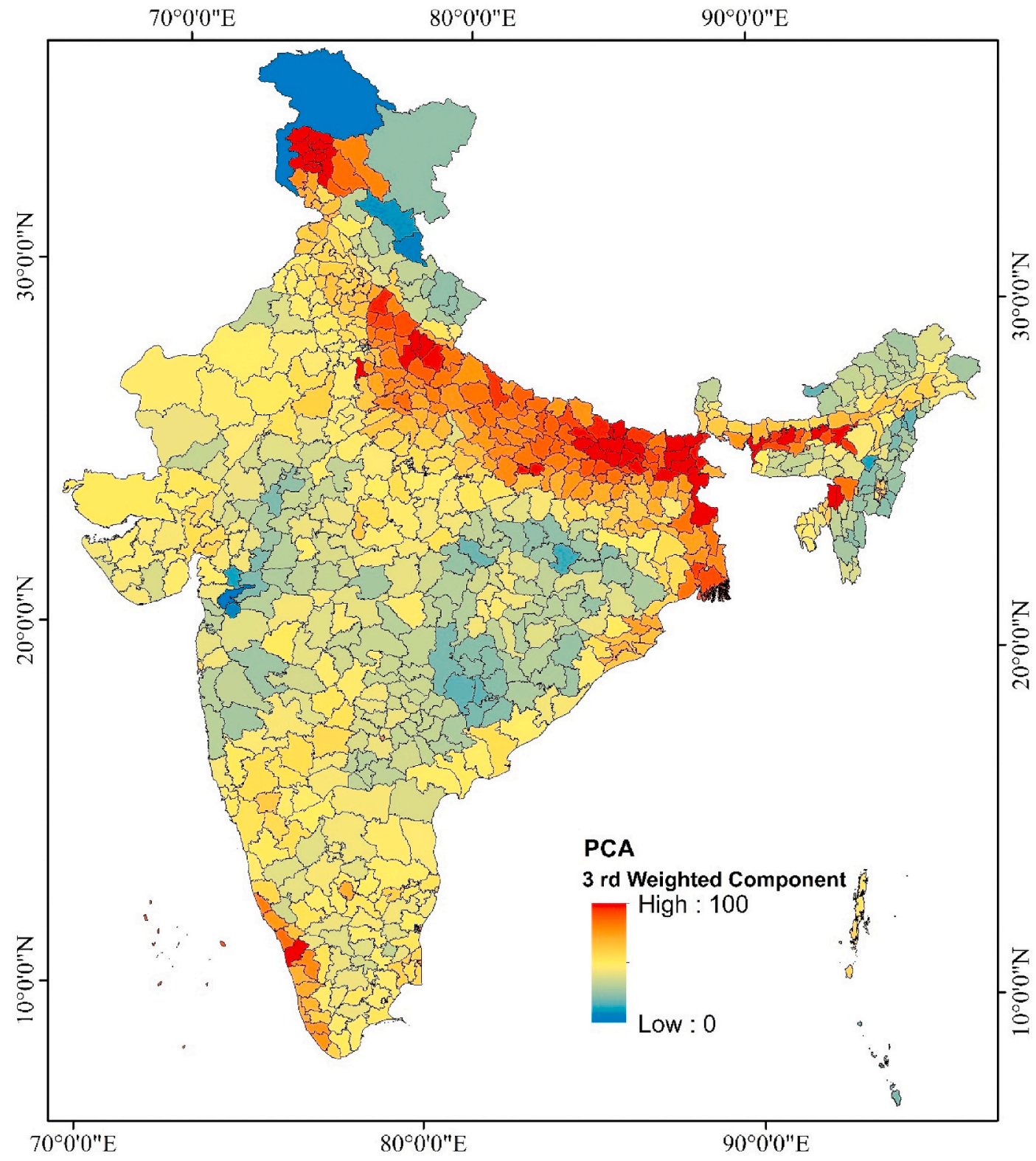

Fig. 8. Socio-Demographic vulnerability.

\section{Results}

Pearson Correlation Matrices of indicators has been represented in Fig. 3. This indicates that population density household density has a strong positive correlation $(>0.5)$ and variables like $\mathrm{PM}_{2.5}, \mathrm{NO}_{2}$ and, $\mathrm{MP}_{10}$ has also high positive relation of $(>0.5)$. Therefore KMO test has been performed to test the suitability of PCA. The test result of the Kaiser-Meyer-Olkin Measure of Sampling Adequacy (KMO) is 0.722 which is greater than 0.5 that significance PAC is appropriate for the analysis. PCA reduces 16 correlated indicators into 4 un-correlated components which are used as sub-indices.

PCA extracted 4-dimension solution with eigenvalue $>1.5,4$ Component which explained $59 \%$ of the variance in the data set. The results obtained from PCA shows that variable associated with air quality- $\mathrm{PM}_{10}, \mathrm{PM}_{2.5}, \mathrm{NO}_{2}$, and $\mathrm{SO}_{2}$ gate high loadings 0.8400 .782 0.7660 .748 respectively in the first component. Socio-economic factors like household density, population density, household having monthly income of height earning member less than 5000, and houseless population obtain high loadings in the second component these are $0.881,0.807,-0.727,-0.513$ respectively (see Table 2 ). On the other hand, workforce participation rate, backward class population, and population belong to SC, ST obtains higher loadings of $0.798,0.762$, $0.723,-0.556$ respectively in the 3rd component. The elderly population, public health infrastructure, literacy, sex ration obtain higher weightage in the 4th component.

Assigning name to the newly created variable is quite difficult here, based on higher loadings of variable 1st component is named as Environment condition, second as Econo-demographic 3rd as social demographic and last one as Geriatric Health Index.

SoEVI index has been constricted combing the above 4 sub-index. Major cities and industrial districts share high vulnerable index North West Delhi (100), Central Delhi (91), Kolkata (91), Mumbai (88), Ghaziabad (71). Gautama Buddha Nagar (73). To test the sensitivity of the SoEVI correlation test and regression test has been performed between normalized index value and normalized active and confirmed cases as on June 25, 2020. Cases' data are highly skewed for high outcrop. Because some districts like Mumbai Delhi, Kolkata, Chennai have very cases and some districts have registered no cases. Therefore Log-transformation has been performed to normalize the data. Boxplot of normalized active, confirmed, recovered, and decreases cases has been represented in Fig. 4. 


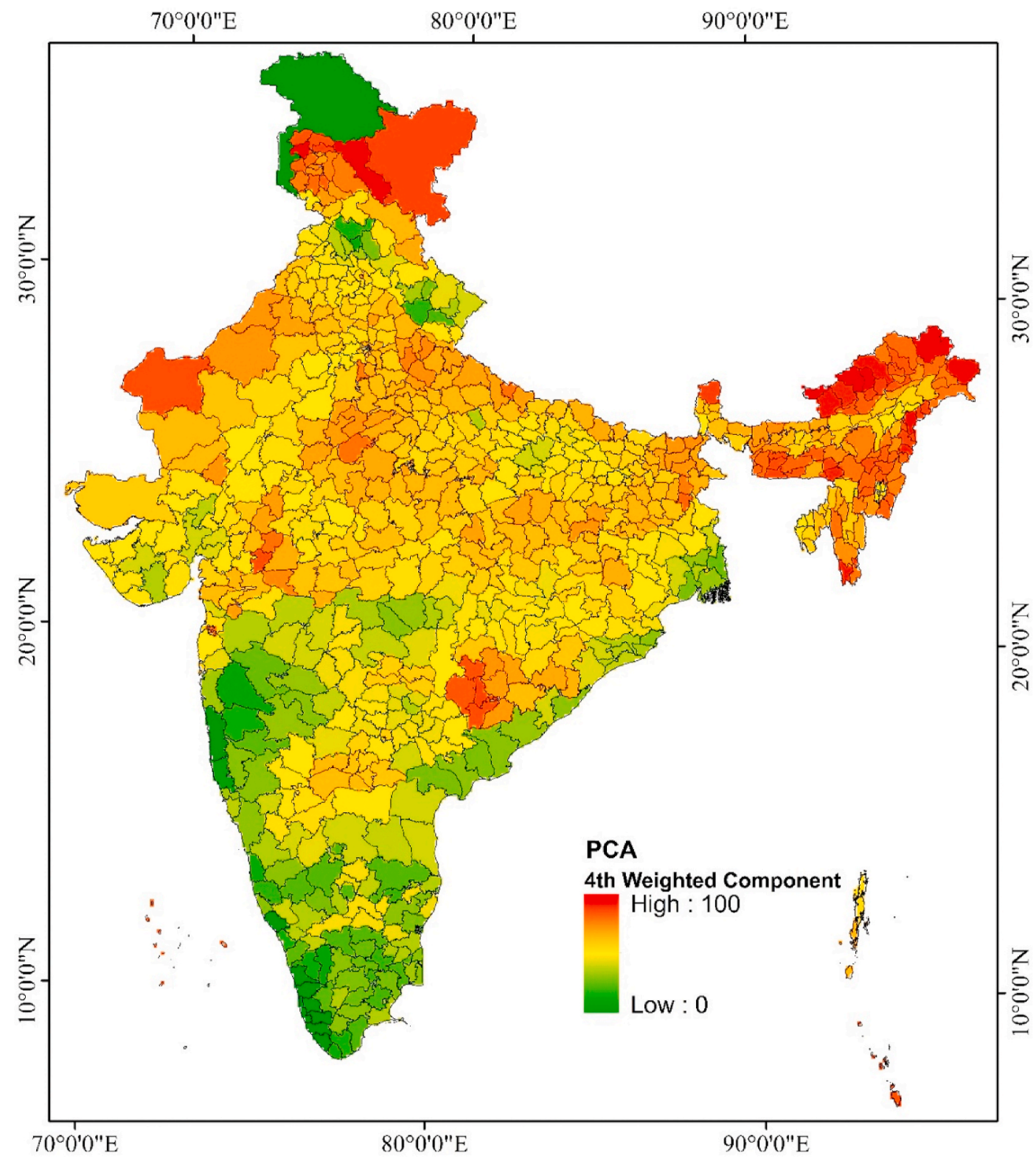

Fig. 9. Geriatric health vulnerability.

We have tried to make a relationship between the vulnerable index and confirmed case and active case as on June 25, 2020 with the help of the Pearson correlation test. We observed a significant positive correlation between SoEVI and active cases is 0.24 and between SoEVI and confirmed cases is 0.381 (Table 3 ). We observer a positive relation between the confirmed and active cases with SoEVI with $\mathrm{R}^{2}$ is 0.099 and 0.067 respectively (Fig. 5). Consequently, this observation proves that the PCA based Social Vulnerability Index of the COVD pandemic is valid.

\section{Discussion}

Sub-index related to Environment represents in Fig. 6 this shows that all the districts of Uttar Pradesh, Delhi, and Rajasthan some part of Maharashtra, and Gujarat included in the highly vulnerable zone. These districts are clustered around the major cites like Kolkata, Delhi, Mumbai, Ahmedabad. District of northeastern states Arunachal Pradesh, Assam, Meghalaya, the district of southern states Kerala, Tamil Nadu, Andhra Pradesh and district located in the central part of India all are fall under moderately to the low vulnerable zone.

In the second principal component related to Econo-demographic factors (Fig. 7) indicates district of northeastern states -Assam, Meghalaya West Bengal, and district of Maharashtra Punjab, Harahan Delhi all are under the high vulnerable zone these district share high population density, household density, high percentage of houseless population and less income group population. Major urban center Kolkata Delhi Chennai, Bangalore, Mumbai, Mumbai suburban also included in this zone for having a share of urban population and high percentage share of the houseless population. Clustering of the low vulnerable zone is found in the northern districts of Uttar-Pradesh across the Nepal border, part of Orissa and Chhattisgarh. Clustering of the low vulnerable districts are observed in the North-Western part of Rajasthan. The clustering of moderate to highly vulnerable districts follows the location of major urban centres.

Different types of clustering patterns have been observed in the 3rd component (Fig. 8). Where socio-economic factors achieved higher weight. Highly vulnerable districts are clustered in northern sate of Jammu Kashmir, Punjab, Haryana Uttar Pradesh, West Bengal, and Assam. Most of the district of southern state Kerala also included in this zone. These districts share high population concentration and low workforce participation and large percentage share of scheduled tribal 


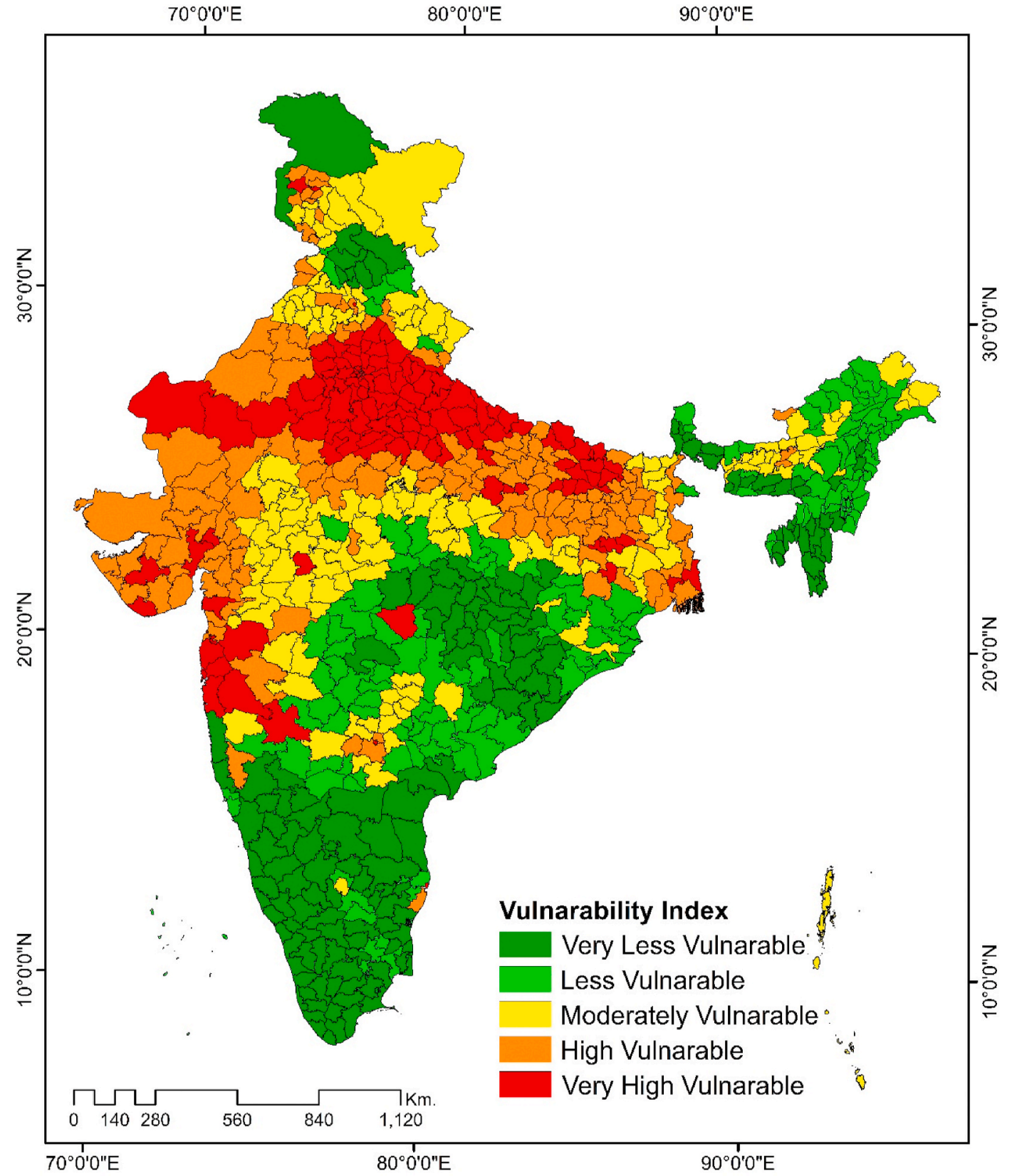

Fig. 10. Socio-environmental vulnerability index (SoEVI).

and scheduled caste population those are an economically unprivileged group. Districts of Tamil Nadu, Andhra Pradesh and Karnataka are found moderately vulnerable.

The 4th component related to Geriatric Health vulnerability where, elderly population and health infrastructure obtain higher loading (Fig. 9). The index shows that most of the south Indian state Kerala, Tamil Nadu, Maharashtra Andhra Parades indicate less vulnerable. On the other hand, most of the districts of the central part of India, districts of the north-eastern part of India are highly vulnerable. Most of the districts of this vulnerable zone coincide with the Empowered Action Group (EAG) states. This vulnerable zone has poor accessibility of public health infrastructure and a low level of education except for the states Mizoram and Tripura.

Fig. 10 depicts the social vulnerability of COVID 19 Pandemic this map displays that a highly vulnerable zone has been clustered in the north and central parts of India most of the district of Punjab, Haryana, Delhi, Uttar Pradesh, Bihar some part of West Bengal. District of Central
India is moderately vulnerable. Most of the districts of Kerala, Tamil Nadu, Chhattisgarh, and most of the districts of Uttarakhand, Nagaland, and Manipur are less vulnerable. This vulnerability reflects the socioeconomic and socio-demographic conditions. There is some sort of dissimilarities among the vulnerability index and a total number of district wise confirmed cases.

In Kerala Tamil Nadu Andhra Pradesh vulnerability index is very low but the number of confirmed cases is high. Because an increase in the total number of cases is largely triggered by other factors like International migration, Nature of working sectors. But high recovery rate of these states reflects the benefit of improved socio-economic condition. The sensitivity analysis reveals that the Socio-environmental Vulnerability Index of the COVD-19 pandemic is valid and it can have a good insight into the phenomena. 


\section{Conclusion}

Addressing a newly emerged pandemic is a challenging task. Where data is not structured and available in such conditions to explore the consequences of socio-environmental and economic on a phenomenon, PCA prove as important decision making tools. It can bring huge multi dimension data into a comparable scale. The PCA Base composite index helps to avoid expert assumptions that minimize the chances of bias. As PCA is based on the mathematical principle that is helpful for decision making. Overall analysis shows that socio-economic factors are an inseparable part of addressing the COVID-19 pandemic. Vulnerability assessment using a composite index can provide an understanding of real-world situations. The vulnerability index has highlighted environmental and socioeconomic backward districts. These areas will suffer more critical problems against of COVID-19 pandemic for their socioenvironmental problem. These districts should be given more priority based on the unprivileged population group. Finally, more research is needed for a more comprehensive outcome.

\section{Funding}

This research received no specific grant from any funding agency in the public, commercial, or not-for-profit sectors.

\section{Declaration of competing interest}

The authors have no competing interests to declare.

\section{References}

1 Gopalan HS, Misra A. COVID-19 pandemic and challenges for socio-economic issues, healthcare and National Health Programs in India. Diabetes Metab Syndr Clin Res Rev. 2020;14(5):757-759. https://doi.org/10.1016/j.dsx.2020.05.041.

2 Zou L, Ruan F, Huang M, et al. SARS-CoV-2 viral load in upper respiratory specimens of infected patients. N Engl J Med. 2020;382(12):1177-1179. https://doi.org/ 10.1056/NEJMc2001737.

3 Li Q, Guan X, Wu P, et al. Early transmission dynamics in Wuhan, China, of novel coronavirus-infected pneumonia. N Engl J Med. 2020;382(13):1199-1207. https:// doi.org/10.1056/NEJMoa2001316.

4 Ohlan R. Pattern of regional disparities in socio-economic development in India: district level analysis. Soc Indicat Res. 2013;114(3):841-873. https://doi.org/ 10.1007/s11205-012-0176-8.

5 Braveman P, Gottlieb L. The social determinants of health: it's time to consider the causes of the causes. Publ Health Rep. 2014;129(SUPPL. 2):19-31. https://doi.org/ 10.1177/00333549141291s206.

6 Lakshminarayanan S. Role of government in public health: current scenario in India and future scope. J Fam Community Med. 2011;18(1):26. https://doi.org/10.4103/ 1319-1683.78635.

7 Gandhi PA, Kathirvel S. Epidemiological studies on coronavirus disease 2019 pandemic in India: too little and too late? Med J Armed Forces India. 2020. https:// doi.org/10.1016/j.mjafi.2020.05.003.

8 Hati KK, Majumder R. Health Infrastructure, Health Outcome and Economic Wellbeing: A District Level Study in India. 2013.

9 How will country-based mitigation measures influence the course of the COVID-19 epidemic? - the Lancet. https://www.thelancet.com/journals/lancet/article/PIIS014 0-6736(20)30567-5/fulltext?utm campaign =tlcoronavirus20\&utm content $=1204$ 03755\&utm_medium $=$ social\&utm_source $=$ twitter\&hss channel $=$ tw-27013292. Accessed June 8, 2020.

10 Team Tncpere. The epidemiological characteristics of an outbreak of 2019 novel coronavirus disease (COVD-19). China CDC Wkly, 2020:2:113-122.

11 Keeling M, Hollingsworth T, Read J. The Efficacy of Contact Tracing for the Containment of the 2019 Novel Coronavirus (COVID-19). medRxiv; 2020.

12 Krishnakumar B, Rana S. COVID 19 in India: strategies to combat from combination threat of life and livelihood. J Microbiol Immunol Infect. 2020;53(xxxx):4-6. https:// doi.org/10.1016/j.jmii.2020.03.024.

13 Wasdani KP, Prasad A. The impossibility of social distancing among the urban poor the case of an Indian slum in the times of COVID-19. Local Environ. 2020:1-5. https://doi.org/10.1080/13549839.2020.1754375, 0(0).

14 Self-isolation for Covid-19 Is Impossible for $40 \%$ of Indian Families. https://www.li vemint.com/news/india/self-isolation-for-covid-19-is-impossible-for-40-of-indianfamilies-11588745543902.html. Accessed June 8, 2020.

15 Paital B, Das K, Parida SK. Inter nation social lockdown versus medical care against COVID-19, a mild environmental insight with special reference to India. Sci Total Environ. 2020;728:138914. https://doi.org/10.1016/j.scitotenv.2020.138914.

16 How Marketers Can Leverage Public Data on Internal Migrants - Blog. https://ho windialives.com/blog/?p=69. Accessed June 8, 2020.
17 Lessons from China: what India can do to flatten the Covid-19 curve despite limited state capacity. https://scroll.in/article/957476/lessons-from-china-what-india-can-d o-to-flatten-the-covid-19-curve-despite-limited-state-capacity. Accessed June 8, 2020.

18 The China way. Use of Technology to Combat Covid-19. https://www.geospatialworl d.net/article/the-sino-approach-use-of-technology-to-combat-covid-19/. Accessed June 8, 2020.

19 Banik R, Rahman M, Sikder T, Gozal D. COVID-19 in Bangladesh: public awareness and insufficient health facilities remain key challenges. Publ Health. 2020;183:50-51. https://doi.org/10.1016/j.puhe.2020.04.037.

20 Buheji M, Cunha C, Beka G, Mavrić B. The extent of COVID-19 pandemic socioeconomic impact on global poverty. A Global Integrative Multidisciplinary Review. 2020;(April). https://doi.org/10.5923/j.economics.20201004.02.

21 Acharya R, Porwal A. A vulnerability index for the management of and response to the COVID-19 epidemic in India: an ecological study. Lancet Glob Heal. 2020. https:// doi.org/10.1016/S2214-109X(20)30300-4, 0(0).

22 Mortality Analyses. Johns hopkins coronavirus resource center. https://coronavirus. jhu.edu/data/mortality. Accessed June 7, 2020.

23 Rafiq D, Suhail SA, Bazaz MA. Evaluation and prediction of COVID-19 in India: a case study of worst hit states. Chaos, Solit Fractals. 2020;139:110014. https://doi.org/ 10.1016/j.chaos.2020.110014.

24 Tomar A, Gupta N. Prediction for the spread of COVID-19 in India and effectiveness of preventive measures. Sci Total Environ. 2020;728:138762. https://doi.org/ 10.1016/j.scitotenv.2020.138762.

25 Lakshmi Priyadarsini S, Suresh M. Factors influencing the epidemiological characteristics of pandemic COVID 19: a TISM approach. Int J Healthc Manag. 2020; 13(2):89-98. https://doi.org/10.1080/20479700.2020.1755804.

26 Chatterjee K, Chatterjee K, Kumar A, Shankar S. Healthcare impact of COVID-19 epidemic in India: a stochastic mathematical model. Med J Armed Forces India. 2020; 76(2):147-155. https://doi.org/10.1016/j.mjafi.2020.03.022.

27 Holand IS, Lujala P, Rod JK. Social vulnerability assessment for Norway: a quantitative approach. Geografisk Tidsskrift. 2011;65(1):1-17. https://doi.org/ 10.1080/00291951.2010.550167.

28 Karaye IM, Horney JA. The impact of social vulnerability on COVID-19 in the U.S.: an analysis of spatially varying relationships. Am J Prev Med. 2020;59(3):317-325. https://doi.org/10.1016/j.amepre.2020.06.006.

29 Aksha SK, Juran L, Resler LM, Zhang Y. An analysis of social vulnerability to natural hazards in Nepal using a modified social vulnerability index. Int J Disaster Risk Sci. 2019;10(1):103-116. https://doi.org/10.1007/s13753-018-0192-7.

30 Gupta S, Raghuwanshi GS, Chanda A. Effect of weather on COVID-19 spread in the US: a prediction model for India in 2020. Sci Total Environ. 2020;728:138860. https://doi.org/10.1016/j.scitotenv.2020.138860.

31 Tsai J, Wilson M. COVID-19: a potential public health problem for homeless populations. Lancet Public Heal. 2020;5:e186-e187.

32 COVID-19 and the impact of social determinants of health. The lancet respiratory medicine. https://www.thelancet.com/journals/lanres/article/PIIS2213-2600(20) 30234-4/fulltext. Accessed June 7, 2020.

33 Feng ZH, Cheng YR, Ye L, Zhou MY, Wang MW, Chen J. Is home isolation appropriate for preventing the spread of COVID-19. Publ Health. 2020;183:4-5. https://doi.org/10.1016/j.puhe.2020.03.008.

34 Ahmed F, Ahmed N, Pissarides C, Stiglitz J. Why inequality could spread COVID-19. Lancet Public Heal. 2020;5(5), e240. https://doi.org/10.1016/S2468-2667(20) 30085-2.

35 Sharma S, Zhang M, Anshika, Gao J, Zhang H, Kota SH. Effect of restricted emissions during COVID-19 on air quality in India. Sci Total Environ. 2020;728:138878. https://doi.org/10.1016/j.scitotenv.2020.138878.

36 CPCB ENVIS| Control of Pollution. http://www.cpcbenvis.nic.in/air_quality_data. html. Accessed June 10, 2020.

37 Singh R, Adhikari R. Age-structured Impact of Social Distancing on the COVID-19 Epidemic in India; 2020. January http://arxiv.org/abs/2003.12055.

38 Godri Pollitt KJ, Peccia J, Ko AI, et al. COVID-19 vulnerability: the potential impact of genetic susceptibility and airborne transmission. Hum Genom. 2020;14(1):1-7. https://doi.org/10.1186/s40246-020-00267-3.

39 Lamba I. Why India needs to extend the nationwide lockdown. Am J Emerg Med. 2020. https://doi.org/10.1016/j.ajem.2020.04.026.

40 Legkauskas V. Recommendations for 'responsible behaviour' is not a sufficient policy tool in public health emergencies. Publ Health. 2020;183(May):15. https://doi.org/ 10.1016/j.puhe.2020.04.026.

41 Faisal K, Shaker A. An investigation of GIS overlay and PCA techniques for urban environmental quality assessment: a case study in Toronto, Ontario, Canada. Sustain Times. 2017;9(3):1-25. https://doi.org/10.3390/su9030380.

42 Faisal K, Shaker A. Improving the accuracy of urban environmental quality assessment using geographically-weighted regression techniques. Sensors. 2017;17 (3). https://doi.org/10.3390/s17030528.

43 Chao YS, Wu CJ. Principal component-based weighted indices and a framework to evaluate indices: results from the Medical Expenditure Panel Survey 1996 to 2011. PloS One. 2017;12(9). https://doi.org/10.1371/journal.pone.0183997.

44 Reckien D. What is in an index? Construction method, data metric, and weighting scheme determine the outcome of composite social vulnerability indices in New York City. Reg Environ Change. 2018;18(5):1439-1451. https://doi.org/10.1007/s10113017-1273-7.

45 Mishra SV. Urban deprivation in a global south city-a neighborhood scale study of Urban deprivation in a global south city-a neighborhood scale study of. Habitat Int. 2018;80(September):1-10. https://doi.org/10.1016/j.habitatint.2018.08.006. 
46 Uddin MN, Saiful Islam AKM, Bala SK, et al. Mapping of climate vulnerability of the coastal region of Bangladesh using principal component analysis. Appl Geogr. 2019; 102(November 2018):47-57. https://doi.org/10.1016/j.apgeog.2018.12.011.

47 Tripathy P, Kumar A. Monitoring and modelling spatio-temporal urban growth of Delhi using Cellular Automata and geoinformatics. Cities. 2019;90:52-63. https:// doi.org/10.1016/j.cities.2019.01.021.

48 Monterroso A, Conde C, Gay C, Gómez D, López J. Two methods to assess vulnerability to climate change in the Mexican agricultural sector. Mitig Adapt Strategies Glob Change. 2014;19(4):445-461. https://doi.org/10.1007/s11027-0129442-y.
49 Rajesh S, Jain S, Sharma P. Inherent vulnerability assessment of rural households based on socio-economic indicators using categorical principal component analysis: a case study of Kimsar region, Uttarakhand. Ecol Indicat. 2018;85(October 2017): 93-104. https://doi.org/10.1016/j.ecolind.2017.10.014.

50 Musse MA, Barona DA, Santana Rodriguez LM. Urban environmental quality assessment using remote sensing and census data. Int J Appl Earth Obs Geoinf. 2018; 71:95-108. https://doi.org/10.1016/j.jag.2018.05.010.

51 Bizimana JP, Twarabamenye E, Kienberger S. Assessing the social vulnerability to malaria in Rwanda. Malar J. 2015;14(1):1-21. https://doi.org/10.1186/1475-287514-2. 